\title{
DỨBin
}

Technological University Dublin ARROW@TU Dublin

2014

\section{Complex Predicates and Light Verb Constructions in Modern Irish}

Brian Nolan

Technological University Dublin, brian.nolan@tudublin.ie

Follow this and additional works at: https://arrow.tudublin.ie/itbinfoart

Part of the Education Commons

\section{Recommended Citation}

Nolan, B. (2014) Complex Predicates and Light Verb Constructions in Modern Irish, Revista Española de Lingüística Aplicada 27:1 (2014), 140-167. doi 10.1075/resla.27.1.06nol issn 0213-2028 / e-issn 2254-6774

This Article is brought to you for free and open access by the Computational Functional Linguistics at ARROW@TU Dublin. It has been accepted for inclusion in Articles by an authorized administrator of ARROW@TU Dublin. For more information, please contact arrow.admin@tudublin.ie, aisling.coyne@tudublin.ie, gerard.connolly@tudublin.ie.

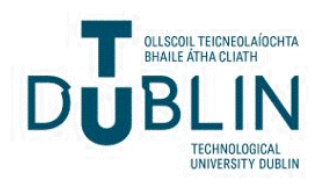




\section{Complex predicates and light verb constructions in Modern Irish Brian Nolan \\ Institute of Technology Blanchardstown, Dublin}

\section{Abstract}

This paper characterises complex predicates and light verb constructions in Modern Irish Light verbs are attested in many of the world's languages (Butt 1995, Butt 2003, Alsina et al. 2001). Cross linguistically, there appears to be a common class of verbs involved in these constructions and generally there is agreement that light verbs contribute to the formation of complex predicates. Light verbs seem have a non-light or 'heavy' verb counterpart. In this paper we discuss the light verb constructions (LVC) as found in modern Irish and how they form complex predicates. We claim that the light verb (LV) encodes the event process verb constructions, the matrix verb appears in Modern Irish syntax as a verbal- . The function of light verbs in these constructions is to modulate the event and sub-event semantics. We distinguish between auxiliary verbs constructions (AVC) and those constructions involving complex predicated and light verbs (Anderson 2006, Aikhenvald and Dixon 2006). We provide evidence based on an analysis of Irish data that shows how aspect and argument structure considerations are resolved for the complex predicate within the light verb construction via the linking system between semantics and syntax. We motivate a functional account, based on Role and Reference Grammar (Nolan 2012, Nolan, and functional account, based on Role and Reference Grammar (Nolan 2012, Nolan, and
Diedrichsen. 2013. Van Valin and LaPolla 1997, Van Valin 2005), that appeals to the analysis of complex predicates within a consideration of the layered structure of the clause.

\section{Introduction}

In this paper we argue that that the light verb within Irish instantiates the process phase change (or cause) and the matrix verb indicates the bounded component or result. In Irish light verb constructions, the matrix verb appears in syntax as a verbal noun form. The function of light verbs in these constructions is to modulate the event and sub-event semantics and different light verbs do so in different ways. From Butt 2003, the intuition behind light verbs is that these constructions appear to be semantically light in the sense that they are contributing something to the joint predication, but not predicating fully. What this contribution is can be difficult to characterise and seems to vary across languages. In Japanese, for example, the light verb construction consists of a light verb and verbal noun (Siegel and Bender 2002), where the verbal noun occurs in a construction with a verb that has only marginal semantic information. We posit, for Irish, that the syntactic, semantic and pragmatic information on the LV complex is a combination of the information within the complete LV construction. The lexical specification of the verbal noun contains argument and situation type information.
To appear in 2014 [Revista Española
de Lingüística Aplicada/Spanish Journal of Applied Linguistics, 27:1]

Evidence from scholars indicates that light verbs seem to have developed from the main verb and the light form of which has lost some of its semantic component through diachronic change. The term complex predicate is used to designate a construction that involved two or more predicational elements (such as nouns, verbs or adjectives), which contribute a single component in that their arguments map into a single monoclausal syntactic structure. The light verb constructions typically affect the aktionsarten of the joint predication and argument sharing across the complex predication. Hopper and Traugott (1993: 108) propose light verbs as an optional stage (1) on the grammaticalization cline.

(1) Full verb $>$ (light verb) $>$ auxiliary $>$ clitic $>$ affix

Anderson (2006:331) proposes a slightly different relationship between lexical verbs, serial, light and auxiliary verb constructions (2).

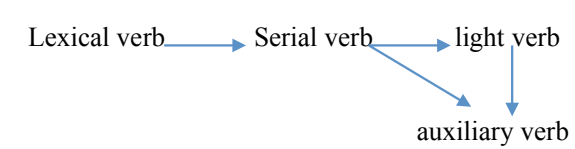

Light verbs contribute to the predication but require a resolution of the argument structure composition, and other elements, within the complex predication. The grammatical structure is that of a single complex predicate. That is to say, light verbs always form a complex predicate. Butt (2003) makes a clear distinction between auxiliary verb constructions and constructions involving light verbs, based on crosslinguistic evidence. Light verbs serve to modulate the event described by the matrix verb in a manner distinct from auxiliaries. Complex predicates allow two or more predicational elements to co-predicate in a monoclausal structure.

In Irish, the light verbs are morpho-syntactically form identical with their main lexical verb equivalent but, at the construction level, they exhibit a particular usage pattern in which a second verbal predicate is involved, the matrix verb. We will discuss this in more detail later within the paper. For Irish, light verbs supply the initial event predication with the matrix verb supplying information about the initial event involved. For example, the particular event type, or the manner in which the event unfolds, along with any means or path details, is contributed to the complex 
predication by the matrix verb and its narrow scope adverbials, rather than the LV. Additionally, the light verb constructions of Irish may encode a cause and result within the complex predication. Importantly, light verb constructions resolve boundedness, telicity, and possibly causation in certain instances, within the complex predicate.

For Irish, we claim that the light verb instantiates the process (or cause), and flags a phase change in the event. The matrix verb indicates the bounded component or result. The function of these light verbs is therefore to modulate the event and subevent semantics. Different light verbs do so in different ways. In the case of Irish, a verbal noun with matrix verb functions is used with the light verb to form the complex predicate. When the verbal noun morpho-syntactic form is used for the matrix verb, the valence is retained. This is fused within the complex predicate with the particular light verb in the light verb construction. Interestingly, LVs can also occur with auxiliary verbs in an AVC construction.

\section{The RRG view of complex predications}

We will argue that an account of the complex predications found in light verb constructions can be provided within the theory of Role and Reference Grammar (RRG). Within the theory, we will appeal to the treatment of coordination, subordination and, importantly, cosubordination. In the RRG model (Van Valin 2005: $183 f f)$, coordination is characterised by the joining of two or more units of equal size and status, and in the case of whole clauses, all of the clauses have the form of dependent main clauses. Subordination involves the embedding of one unit within another. RRG therefore posits three nexus relations (coordination, subordination and cosubordination) between units in complex sentences. The essential property distinguishing cosubordination from coordination is operator dependence in that all the shared operators are clausal operators. According to Cristofaro (2003:23), coordination is characterised by the absence of both dependency and subordination; subordination involves both. Cosubordination, however, draws from elements of both coordination and subordination. Like coordination, cosubordination involves no embedding and, like subordination, it involves dependency. Cristofaro (2003:23) argues that cosubordination may be seen as occupying an intermediate position in a continuum having coordination and subordination as opposite poles.

Nexus relations are therefore the syntactic relations between the units in a complex construction. Related to nexus relations is the nature of the units being linked, that is, the juncture types within RRG. Linkage of subclausal units is common in complex sentences cross-linguistically. The subclausal units of interest are those within the RRG conception of the layered structure of the clause and, within the literature, these nexus-juncture relations have acceptance and application. For example, Anderson (2006:9ff) appeals to core and nuclear juncture formations in his account of complex predications involving auxiliary verbs constructions (AVCs) and uses these abstractions to distinguish the AVCs from serial verb constructions (SVCs). Aikhenvald (2006: 50) and Solnit (2006: 146) apply elements of nexus-juncture relations in their respective accounts of SVCs. We will apply the nexus-juncture relations (3), and related parts of the RRG model, to further our account of light verb constructions of Irish.

(3) The nexus-juncture relations

\begin{tabular}{|l|l|}
\hline Nuclear juncture & {$[\mathrm{CORE} \ldots[\mathrm{NUC} \ldots] . .+\ldots[\mathrm{NUC} \ldots] \ldots]$} \\
\hline Core juncture & {$[\mathrm{CLAUSE} \ldots[\mathrm{CORE} \ldots] . .+\ldots[\mathrm{CORE} \ldots] \ldots]$} \\
\hline Clause juncture & {$[$ SENTENCE $\ldots[\mathrm{CLAUSE} \ldots] . . . . .[\mathrm{CLAUSE} \ldots] \ldots]$} \\
\hline
\end{tabular}

Light verbs in Irish are to do with encoding a phase change, i.e., initiation, of the event and the matrix verb, in VN form, determines the type of event. The argument structure is resolved by fusion of the logical structures (LS) of the LV and VN predicates in a principled manner, i.e., [BEGIN [BECOME do' $(x,[\ldots y . .])$.$] , where y$ is a LS. The boundedness of the event is determined by the contribution of the $\mathrm{VN}$ to the overall predication. This is explicated within the RRG model via nexus-juncture relations and the application of the linking system.

The light verbs of Irish are not bleached just for argument structure when they appear as part of a complex predicate but also for aspect and event structure. The light verbs have a lexical specification containing a logical structure and may be intransitive or transitive. 


\section{The facts about the light verb data in LVCs}

Light verbs occur in clauses of Irish with the following (4) clause grammaticalisation patterns. The differences are due to the transitivity of the non-light verb. In addition, the preposition $a g$ 'at' is optional in intransitive clauses of this nature. The non-light verb, the matrix verb, is in the morphosyntactic form of a verbal noun $(\mathrm{VN})$ in this construction. This use of a nominalised form of a lexical verb is particular to the Celtic languages (Anderson 2006:60ff, 98).

\section{(4) $\quad$ a. $\quad \mathrm{V}_{1} \mathrm{NP}\left(\right.$ Prep) $\mathrm{V}_{2}$ (NP)}

Where, depending on the transitivity of the $V_{2}$, this will be of the following actual grammatical form as a light verb construction.

b. $\quad \mathrm{LV}_{1} \mathrm{NP}$ ag $\mathrm{VN}_{2} \mathrm{NP} \quad$ (transitive $\mathrm{VN}$ )

c. $\mathrm{LV}_{1} \mathrm{NPVN} \mathrm{VN}_{2} \quad$ (intransitive $\mathrm{VN}$ )

Where VN means verbal noun

We will use the notation $L V$ to refer to the light verb instead of $\mathrm{V}_{\mathbf{1}}$, and $\mathrm{VN}$ to refer to the non-light verb instead of $\mathrm{V}_{2}$. A preliminary example of this type of construction is shown in (5), following. In this example the optional preposition ag 'at' is used. We will introduce more data examples later within the paper across a number of verbs.

(5) Thosaigh an traein ag bogadh ar aghaidh

start-PST DET train:N at:PREP moving:VN on:PREP forward:Adv

go mall

to:PrEP slow:Adv

The train started moving forward slowly

While the clause has two verb forms in it, the construal in this particular clausal construction is that of a single event predication. In RRG terms this means that the clause has a single event logical structure and the various arguments are linked to the single predication of the event in a principled way. Additionally, the class of verbs (6) that seems to occur within this light verb construction have characteristics in common in that they are concerned with 1) causation and/or 2) the start, continuation of process, or termination of the event, whatever its particular event type. In this regard, the verbal noun form within the clause denotes the type of the event itself, as this information of contributed by the semantics of the particular matrix verb. All of the light verbs within this class have 'heavy' counterparts. In turn, the means, manner or path of the verbal action may be denoted by an adverbial phrase with a narrow scope over the $\mathrm{VN}$ component of the event predication and not over the light verb. In this sense, therefore, the first verb form, the light verb, is semantically bleached in that it does not provide information on the nature of the event, or its manner, means, position or path.

(6) Members of the class of verbs that can form LVCs

Déan 'do/make'
Thósaigh 'start'
Ceadaigh 'let'
Lig 'allow'
Éirigh 'rise'
Iarraigh 'try'
Tóg 'take'
Gabh 'take'
Tabhair 'give'
Chuir 'put
Chaith 'spend
Buail 'hit'
Téigh 'go'
Seas 'stand'
Coinnigh 'continue'
Stad 'stop'

It would also seem to be the case that members of the class of verbs of motion and path do not partake in light verb constructions, with one exception, the verb téigh 'go'. We merely highlight this fact here but discuss it, with examples, later in the paper. Some members of this category of verbs of motion and path class are indicated in (7), below. 
(7) Members of the category of Irish verbs of motion and path that cannot form LVCs

Saothraigh 'do/obtain'

Glac 'take'

Géill 'yield'

Aimsigh 'hit'

Iompaigh 'turn'

Tiontaigh 'turn'

Imigh 'depart'

Tar 'come'

Téigh 'go'

This class of light verbs of interest to us here is concerned with phase change with respect to the event denoted in the clause, and with informing or modulating the subevent semantics in some way.

Phase verbs make reference to a particular part or phase of an event construal. This requires a means of conceptualising the sub-event semantics. Following Toraton (2002) and Freed (1979), we can usefully consider an event as decomposing into three temporal segments, or sub-event parts: an event ONSET, a event NUCLEUS, and an event CODA, with the event NUCLEUS further divided into INITIAL, MIDDLE, an FINAL. However, the first two terms are potentially ambiguous with other senses in linguistic theory in that 'onset' is used to denote the starting point, and NUCLEUS in RRG refers to a syntactic unit. Toratani, to avoid terminology confusion, renames them as 'PREINCEPTIVE', following Binnick (1991), and 'MAIN EVENT' Toratani also calls the INITIAL as INCEPTIVE in order to be consistent with PREINCEPTIVE. A general schema of the internal phases of an event can be presented as in Figure.1.

The PREINCEPTIVE is the temporal segment where the event has not completely started yet but may imminently be starting. The MAIN EVENT is the 'progressing' phase of the eventuality, which can be further divided into: INCEPTIVE, MIDDLE, and FINAL. According to Freed (1979), the INCEPTIVE phase is not qualitatively distinct from the rest of the phases. If the event has already set in at this phase but was interrupted, then it is accurate to state that the event was in progress. Toratani contrasts this with PREINCEPTIVE, where cancellation of the event at the PREINCEPTIVE phase does not entail that the event was in progress. The MIDDLE and FINAL phases are the phases past the INCEPTIVE phase. The CODA can be thought of as the post-event phase.

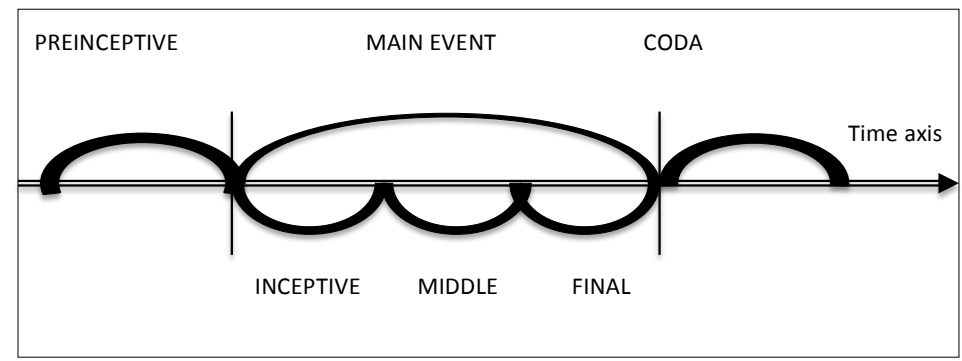

Figure 1: General schema of the internal phases of an event (following Toratani 2002)

In RRG terms, these phase characteristics are captured within the interclausal semantic relations (8) and the interclausal relations hierarchy (Van Valin 2005: 211) and, with the syntactic juncture-nexus types, are used to express certain semantic relations between the units in the juncture, for example, causation, phase, purpose and temporal sequence.

With phase, for example, a separate verb describes a facet of the temporal envelope of the SoA. These relations have been given a formal characterisation in Van Valin (2005: 207). For purposes of the paper, we can see that the semantic elements pertaining to the verbs under discussion are to be found at the top part of this hierarchy. This is, we claim, no accident and we will refer to this in our analysis of the data. The interclausal semantic relations are listed as follows, from Van Valin (2005: 206); we have highlighted in bold the elements under discussion.

An additional fact pertaining to these light verbs is that they can occur within auxiliary verb constructions and, when this occurs, the light verb itself also takes on 
the morphological form of a verbal noun. The AVC, therefore, exhibits the clausal pattern in (9). The AVC may have two LVs in sequence, both in VN form. There is some variation within this pattern to do with the transitivity, for example, of the rightmost verbal form, which describes the event type, as per our earlier observation. We provide an initial example in (10) of an AVC construction that uses a light verb and will discuss these in more detail later in the paper.

(8) Interclausal semantic relations

a. Causation [1]

b. Phase: a separate verb describes a facet of the temporal envelope of the states of affairs (SoA)

c. Modifying subevents

1: manner

2: motion

4: means

d. Psych-action

e. Purposive

g. Causative [2]

h. Direct perception

i. Indirect perception
j.

j. Propositio

Indirect discourse

m. Direct discourse

n. Circumstances

o. Reason

p. Conditional

q. Concessive

1: simultaneous SoA

2: sequential SoA

s. Temporally unordered SoA

(9) Syntactic construction signatures of AVCs utilising a light verb in Irish

a. AUX NP LV VN

b. AUX NP (ag:PreP) LV $V_{\mathrm{VN}} \mathrm{NP}$

c. AUX NP (ag:PreP) LV LN (ag:PreP) VN NP

Where, in the AVC construction, the light verb - $\mathrm{LV}_{\mathrm{VN}}$ - is found in the morphosyntactic form of a verbal noun.
AUX-PST Trevors:N at:PREP attempting:VN escaping:VN

trasna

$$
\text { na bpáirceanna. }
$$

across:PREP DET park:N

LIT: Trevors was attempting escaping across the park.

Trevors was attempting an escape across the park.

In the next section we provide data examples for each of the verb class mentioned as relevant to light verbs, with a discussion.

\section{The examples of light verbs in Irish}

We have made the claim that the class of verbs that lend themselves to use within light verb constructions have a number of important elements in common. They are semantically bleached in certain characteristics to do with the designation of the even type, they form part of a single predication, and have to do with the encoding of causation, denotation of phase or the modulation of the event and possibly the manner, means, motion or path of the event. We also noted that lexical verbs of motion and path do not generally seem to be amenable to use as light verbs. We noted one exception to this. In this section we provide data examples of each of the verbs mentioned that can occur as light verbs. We will also provide later a detailed analysis of a representative number of the examples. We begin with the verb rinne which can allow an interpretation of either 'do' or 'make' according to context. The 'make' reading is causative. We gloss this verb as 'do.make' or simply 'make' as appropriate.

(11) Rinne duine ionsai ar Threvors

Make-PST person:N attacking:VN on:PREP Trevors:N

$$
\text { san áit sin. }
$$

in:PREP+DET place:N that:DEM

A person made an attack on Trevors in that place.

in.that.place' $\left[\left[\mathbf{d o}^{\prime}(\right.\right.$ person, $Q$ ), [make.attack'(person, Trevors)])]]]

In this example (11) of rinne, we have an explicit actor coding for both agency and volition. The actor is a shared argument over both verbal predicates. In figure 2 we provide an RRG structural representation of the nexus-juncture relations. We can see that this example is a nuclear juncture with two nuclei residing under a topmost 
nucleus within the clausal core. The nuclear operators are shared across the verbal predicates, in this instance the operator codes tense. The actor NP is a shared argument of both verbal predicates and the undergoer is clearly indicated. The locative adverbial indicates the place where the event occurred. As this has wide scope it is therefore positioned at the topmost nucleus and ranges over the complete event.

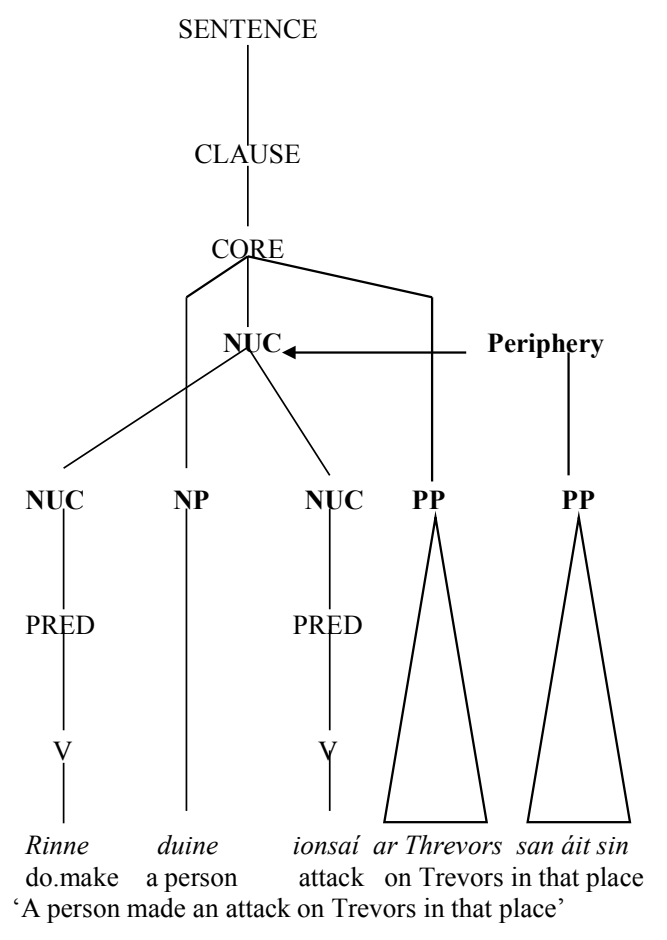

in.that.place' $\left[\left[\right.\right.$ do'$^{\prime}($ person, $Q)$, [make.attack'(person, Trevors)])]]]

Figure 2: Nuclear cosubordination of complex predicate (Example 11)

Use of the verb rinne in this way is reasonably productive and examples (12) and (13) demonstrate this pattern and phenomena. It can also be used within a yes-no question construct (14)

(12) Ansin rinne na páistí gáire.

then:Adv do.make:-PST DET-PL children:N laughing:VN
LIT: Then the children made laughing.

Then the children laughed.

then'[do'(the children, $Q$ ), [made.laugh'(the children)]]

(13) Déaneann mé scrúdú uirthi

do.make-PRS 1SG examining:VN on:PREP+3SG.F

LIT: I did make examining on her.

I made/did an examination on her.

(14) An ndearna tú scrúdú air?

DET do.make-PST 2SG examining:VN on:PREP+3SG.M

LIT: Did you do/make examining on it

Did you examine him/it?

The next example of interest is to do with phase rather than causation, as we indicated within the interclausal semantic relations hierarchy. The verb here is thosaigh 'start'. In example (15), we can observe that there is a shared argument said go leir 'they all' between both verbal predicates. The first verbal predicate, the LV, is intransitive while the matrix verb, in $\mathrm{VN}$ form, is also intransitive. We can note that agency exists with the shared argument as the participants and animate and volitional. Similarly in (16) we have a shared actor argument and we can observe that agency exists. The major difference with this example in contrast to the previous one is that the matrix verb is transitive and an undergoer can be identified as cluiche peile 'game of ball = football'.

(15) Thosaigh siad go leir ag troid.

start-PST 3PL to:PREP all:QTY at:PREP fighting:VN

They all started fighting

[do'(they.all, [start'(they.all, [fight'(they.all) ] ) ] ) ]

(16) Thosaigh siad ag imirt cluiche peile. start-PST 3PL at:PreP playing:VN game:N ball:N

They started playing a game of football

[do'(they, [start'(they, [play'(they, football) ] ) ] ) ]

A shared argument is also to be found in (17), similar to above, and the same discussion applies. In this instance, however, we can note that two adverbial phrases 
with narrow scope modify the matrix verb and not the light verb. The adverbials provide phase related information on the manner of motion and path of the action (see figure 3). There is an implied agency over the initial inanimate shared argument. However, this argument an traein 'the train' is actually an effector.

(17) Thosaigh an traein ag bogadh ar aghaidh start-PST DET train:N at:PREP moving:VN on:PREP forward:Adv

go mall.

to:PreP slow:ADV

The train started moving forward slowly

do'(train, [start'(train, [move'(train) ]

$\wedge$ manner.of.motion.slowly'(train) $\wedge$ path.forward'(train) ) $])]$ SENTENCE

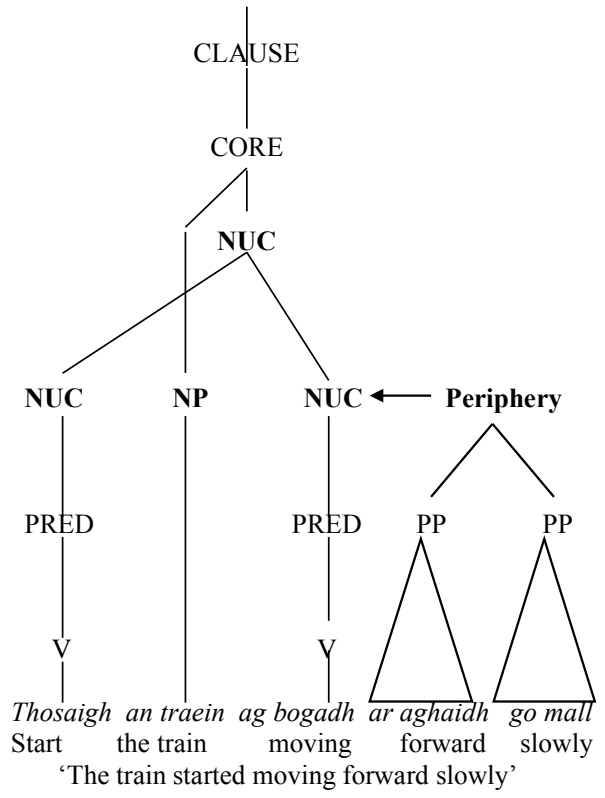

Figure 3: Nuclear cosubordination of complex predicate (example 17)

(18) Thosaigh sé ag foghlaim Béarla.

Start-PST 3SG.M at:PREP learning:VN English:N
He started learning English.

do'(he, [start'(he, [learn'(English)

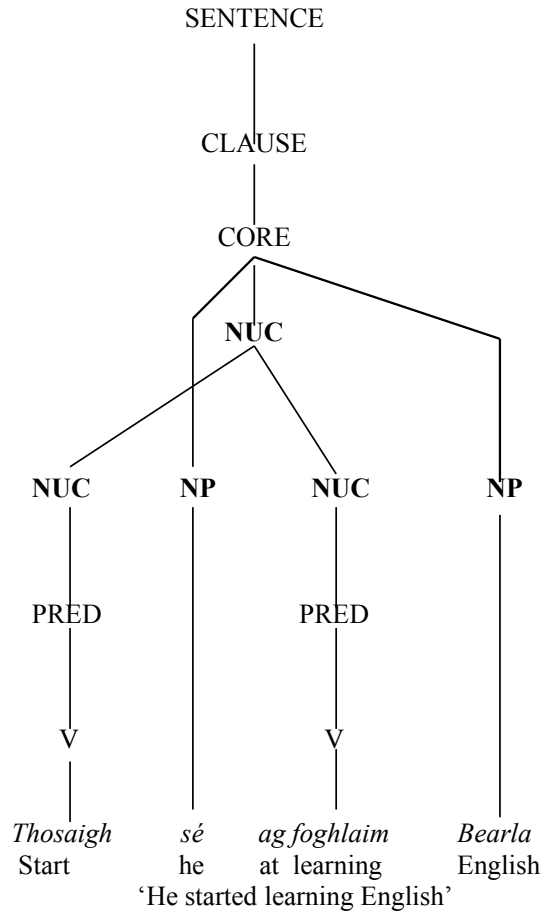

Figure 4: Nuclear cosubordination of complex predicate (Example 18) A verb somewhat analogous to thosaigh 'start' is thaifigh 'begin' and we provide an example of this in (19). This behaves in exactly the same manner as the examples above.

(19) Taifeadadh Findlay ag canadh amhrán seicteacha.

Begin-PRS Findlay:N at:PREP singing:VN song: $\mathrm{N}$ seventies:AD

Findlay began singing a seventies song. 
We now provide a data example for each of the members of the class of verbs that can form LVCs, as indicated in (6) above. These examples following allow for the same analysis as given for examples (11), (17) and (18) and figures 2, 3 and 4.

(20) Buailfidh mé ag siúlóid Hit-FUT $1 \mathrm{SG}$ at:PREP walking:VN go dtraothfaidh mé mo bhéili. to:PREP digest-FUT 1SG my:PN-POSS meal:N

LIT: 'I will hit at walking until I will digest my meal'.

I will start walking until I digest my food.

(21) Chaith John seacht mbliana ag canadh Spend-PST John:N seven:NUm years:N.PL at:PREP singing:VN leis an ngrúpa 'The Stargazers'. with:PREP DET group:N 'The Stargazers':NP John spent seven years singing with the group 'The Stargazers'.

(22) Sheasfá sa sneachta ag éisteacht Stand-COND+1SG in:PREP+DET snow:N at:PREP listening:VN léi. to:PreP+3SG.F

I would stand in the snow listening to her.

(23) Stad mé féin den tsniomhachán Stop: V-Past I:PN self:Refx.Intensifier of:Prep+the:DET spinning:VN I myself stopped the spinning.

(24) Coinnionn sé ag cur ceisteanna ort. Continues-Prs 3SG.M at:PreP putting:VN questions:N to:PreP+2sg He continues putting questions to you.

(25) Coinnionn sé air ag ól.

Continues-PRS 3SG.M on:PREP+3SG.M at:PreP drinking:VN Lit: 'He continues on his drinking'.

He continues his drinking.
Example (26) and (27) indicate a lexical causative, (28) indicates manner path, while (29) and (30) indicates an instance of the impersonal passive within a light verb construction. Example (31) indicates the event path source trajectory.

(26) Chuireas roinnt laethanta dorcha isteach Put-PST+1SG some:QTY days:N.PL dark:ADJ inside:ADV
ag gabháil
de ghnáthobair
na hoifige.

at:PREP attending:VN to:PREP business:N+work:N (of) DET office:N

I put in several dark days inside attending to office work.

[do'(I) CAUSE [BECOME (attend'(I) $\wedge$ [be-at'(office work, I)]]

(27) Cuirfidh muid ag snámh iad.

Put-Fut 1PL at:PREP swimming:VN 3PL

We will put them swimming.

[do'(we) CAUSE [BECOME (swim'(them)]]

(28) D'éirigh said leis sin éalú

Rise-PST 3PL with:PREP that:DEM escaping:VN

ar a bhealach féin abhaile

on:PrEP a:PN-POSS way:N RFX-PART home:N

go Cúige Uladh.

to:PrEP province:N Ulster:N

LIT: They arose then with escaping on their own way home to Ulster

They then succeeded escaping in their own way home to Ulster

$\left[\mathbf{d o}^{\prime}\right.$ 'they, [rise'(they, [escape'(they) $\wedge[$ be-at'(home, they) $] \wedge$

[path.of.escape'(to Ulster)] $\wedge$ [manner.of.esape'(in their own way)]])])]

This example (28) indicates the encoding of manner and path as well as the destination location.

(29) Tosaiodh ag gabháil de chiceanna agus Start-IMP-PASS-PRS at:PREP going:VN with:PrEP kicks: $\mathrm{N}$ and de bhuilli orm.

with:PrEP blows:N on:PrEP+1SG

Someone started going with kicks and blows on me. 
(30) Tógadh liú mór

Take-IMP.PASS-PST shouting:VN big:ADJ when:COND REL
chonacthas
an Tánaiste ag
iarraidh
fuinneog a

see-IMP.PASS-PST DET chief:N at:PREP attempting:VN window:N REL

bhriseadh.

breaking:VN

Lit: Someone took a shout when they saw the chief attempting the breaking of the window.

Someone shouted when they saw the chief attempting the breaking of the window.

The examples in (29) and (30) of tosaigh 'start' and tóg 'take', respectively, are particularly interesting in that the light verb uses the impersonal passive voice. All verbs of Irish, with the sole exception of the copula, can take the impersonal passive form, across all tenses. What is important here is that it can occur within a light verb construction. In the impersonal passive of Irish, the verb marking encodes specificity and indefiniteness, as well as tense. Irish has a personal passive form as well as the impersonal.

(31) Lig Kenneth liu as.

Let-pst Kenneth:N shouting:VN from:PreP+(3SG.M)

LIT: Kenneth let shouting out

Kenneth let out a shout.

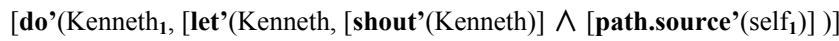

(32) Thug si iarraidh labhairt.

Give-PST 3sG.F attempting:VN speaking:VN

LIT: She gave an attempt at speaking.

She attempted speaking.

[do'(she, [give'(she, [attempt'(she, [speak'(she)] )])])]
(33) Uaireanta, téann sé ag snámh

frequently:ADV go-PRS 3SG.M at:PrEP swimming:VN

Occasionally, he goes swimming.

Occasionally'[do'(he, [go'(he, [swim'(he)])])]

(34) Ragham ag fiach.

Go-FuT+3PL at:PrEP hunting:VN

We will go hunting.

[do'(we, [go'(we, [hunt'(we)])])]

We can see from the analysis of these examples that the nature of the event, the type itself, is provided by the matrix verb and that this occurs in VN form within the LVC. The LV is concerned with the initiation, continuation or completion of the event, that is, its phase. We have also argued that the RRG conception of cosubordination in the nexus-juncture relation is the most effective way of explaining the LV behaviour, in particular, the resolution of argument sharing within the complex predication. The particular nexus-juncture relation involved in LVCs is nuclear cosubordination. We have also discussed examples within the LVC of nuclear cosubordination where the means, manner, position or path is included with narrow scope on the matrix verb.

As we will see next, some additional evidence to support our analysis comes from examining the exceptions, that is those verbs of motion and path that cannot form light verbs constructions.

\section{Exceptions - verbs of motion and path that cannot form LVCs}

As we mentioned earlier, there is a class of verbs in Irish that at first glance we might expect to behave as light verbs, but do not. These are the class of verbs of motion and path and, like many of the earlier mentioned verbs, have to do with phase initiation of a motion event or its continuation in a path of some kind. As Levin (1993:263ff) notes, the lexical meaning of these verbs include, along with the specification of some kind of event, a specification of the direction of motion, even if that motion is simply towards or away from the event participant.

We might speculate that it is precisely because of the lexical specification of specific event type that members of this verb class cannot occur as light verbs within LVCs. 
This is evidence to support our hypothesis. Some representative examples from this class - which do not exhibit the light verb phenomena - include the following (35-42) and the verb under discussion is underlined in each. We provide a logical structure representation for several to indicate path and manner information, as necessary to support the discussion. Note: These examples are simply to illustrate members of the class - they are not LVCs.

(35) Shaothraigh si a MA in Education

Cultivate-PST 3sG.F her:PN-POSS MA in Education

leis an Open University.

with:PREP DET Open University.

She obtained her MA in Education from the Open University.

(36) Glacann an fear lámh dheas na mná

Take-PST DET man:N hand:N right:ADJ (of).DET woman:N

ina láimh féin.

in:PREP+his:PN-POSS hand:N REFX-PRT

The man took the right hand of the woman in his own hand.

(37) a. Nior ghéill sé di.

NOT:NEG yield-PST 3SG.M to:PREP+3SG.F

He would not yield to her

b. Tá an chré bog agus géilleann

Be-PRES DET grave:N soft:ADJ and yield-PRS

sí go h-éasca.

3sG.F to:PREP easy:AD

The grave is soft and it yields easily.

(38) $\mathrm{Ag}$ an am céanna, d'iompaigh roinnt Lochlannaigh

at:PREP DET time:N same:ADJ turn-PST several:QTY Vikings:N

ón bPágánacht go dtí an Chriostaiocht.

from:Prep Paganism:N to:Prep at:PREP DET Christianity:N

At the same time, several Vikings turned from Paganism towards Christianity.

At.the same.time'(do'( Vikings, [turn'( Vikings)])

$\wedge \neg[$ be-at'(Paganism, Vikings)])

$\wedge$ [BECOME [be-at'(Christianity, Vikings)]
(39) Tháinig muid ar saoire cois na farraige. Come-Pst 1PL on:PrEP holidays:N beside:PREP DET sea:N

We come on holidays beside the sea.

$\left[\mathbf{d o}^{\prime}\left(\right.\right.$ we,$\left[\right.$ come $^{\prime}($ we $\left.\left.)\right]\right) \wedge[($ BECOME [be-at' (holidays, we $)]$ $\wedge[$ (BECOME [be-at' (the sea, we $)]]$

(40) Dé hAoine, téann sé go dti

Day:N Friday:N go-PRS.HAB 3SG.M to:PrEP.to:PREP

an teach tábhairne.

DET house:N bar:N

On Fridays, he goes to the pub.

on.Friday'(do' (he, [go' (he)]) \& INGR [be-at'(pub, he)])

(41) a. D'imigh an scáth as tóin a

Go.depart-PST DET shadow:N from:PREP base:N of:PREP

'tsléibh.

mountain:N

The shadow cleared from the foot of the mountain.

$\left[\mathbf{d o}^{\prime}\left(\theta,\left[\mathbf{g o}^{\prime}(\right.\right.\right.$ shadow $\left.\left.)\right]\right)$

$\wedge$ NOT (INGR [be-at'(foot of the mountain, shadow)])]

b. I lár na 18ú aoise, d'imigh an-chuid Protastúnaigh go Meiriceá, ina measc siúd baill na hEaglaise Módhaigh (Methodists) agus Cuman na gCairde (Quakers) ar thóir saoise creidimh san cóilini nua.

In the middle of the $18^{\text {th }}$ century, many Protestants went to America, majority of them members of the Methodists and Quakers seeking freedom of religion in the new colonies.

b) d'imigh an-chuid Protastúnaigh go Meiriceá go.depart-PST many:QTY Protestants:N to:PREP America; $N$ Many Protestants went to America.

[do' (many Protestants, [go' (many Protestants)])

$\wedge$ (INGR [be-at'(America, many Protestants)])] 
(42) Agus mé ag léamh roinnt blaganna anseo ar Blogger, d'aimsigh mé roinnt dánta atá thar a bheith iontach le fear darb ainm Colm (ní fios a shloinne).

And me reading various blogs here on Blogger, I hit upon various poems that were wonderful by a man whose name is Colm (I don't know his title).

We now examine auxiliary verb constructions where the light verb is utilised.

\section{Auxiliary verb constructions that utilise light verbs}

We can usefully provide a brief contrast of the LVC discussed earlier with some auxiliary verb constructions (AVCs). Auxiliary verb constructions are defined by Anderson (2006: 7) as a "monoclausal structure minimally consisting of a lexical verb element that contributes lexical content to the construction and an auxiliary verb element that contributes some grammatical or functional content to the construction". AVCs therefore represent a cluster of syntactic, semantic and morphosyntactic features. We can see this in the data and more particularly in the Aux constructional schema presented in (48), later.

There are many different types of auxiliary verb constructions within Irish but we will only discuss the AVCs that use light verbs. These AVCs of Irish involve the same light verbs as discussed earlier but employ them in the morphosyntactic form of verbal noun within the AVC. These AVCs express imperfectivity and the progressive.

The auxiliary verb used is one of the forms of the verb 'to be' in Irish, the other form of 'to be' being the copula is 'be'. The auxiliary verb here can record tense. This noncopula form of the verb 'to be' has a number of functions and it is also occasionally called the existential verb. As it provides auxiliary functions here we will label it in the gloss as Aux. The Aux may also express a negative or positive polarity. The AVC construction involves the nominalised form of the lexical verb, that is, as a VN within the construction [Aux VN].

The AVCs differ from LVCs in a number of important characteristics, apart from those mentioned earlier. The AVC includes an auxiliary verb that encodes tense (an operator in the layered structure of the clause (LSC) in RRG) and possibly negative polarity (also an operator) whereas in an $\mathrm{LVC}$, the tense is recorded on the light verb. In both construction types, the operators are projected across the whole construction. Within this AVC type, the construction encodes progressive aspect and, as we have see in figure 1, this denotes the progressing transition from PREINCEPTIVE to INCEPTIVE in the sub-event phases. In the AVC type under discussion - those that utilise LVs - the INCEPTIVE phase of the sub-event is not yet reached, within the main event construal.

Of interest too is that we can directly relate the AVC construction to the grammaticalisation patterns portrayed in (1) and (2). Here we can record the observation that there is no evidence for a serial verb construction in Irish, but that the [lexical verb - light verb - auxiliary verb] continuum is productive. Under this, the auxiliary verb construction is more grammatical in nature than the LVC. However, the resolution of the LVs themselves is lexical in nature. We will discuss the criteria by which we argue this in (53), later.

The actual patterns of occurrence are in (43).

(43) Syntactix constructional signatures of AVCs utilising light verb a. AUX NP LVVN

b. AUX NP (ag:PreP) LV $V_{V N} N$

c. AUX NP (ag:PreP) LV $V_{\text {VN }}$ (ag:PreP) VN NP

Where, in the AVC construction, the light verb $-\mathrm{LV}_{\mathrm{VN}}$ - is found in the morphosyntactic form of a verbal noun.

In Irish, the preposition $a g$ 'at:PREP' in this function encodes for progressive aspect. We see this when it occurs in the construction [ag VN].

We now provide some examples of each $(44,45$, and 46$)$ that illustrate the patterns of occurrence of AVCs, utilising light verbs, along with RRG structural representations of the constituent and operator projections showing the nuclear cosubordination. 
Aux-PST Trevors:N at:PREP attempting:VN escaping:VN

trasna

$$
\text { na bpáirceanna }
$$

across:PREP DET park:N

LIT: Trevors was attempting escaping across the park.

Trevors was attempting an escape across the park. SENTENCE

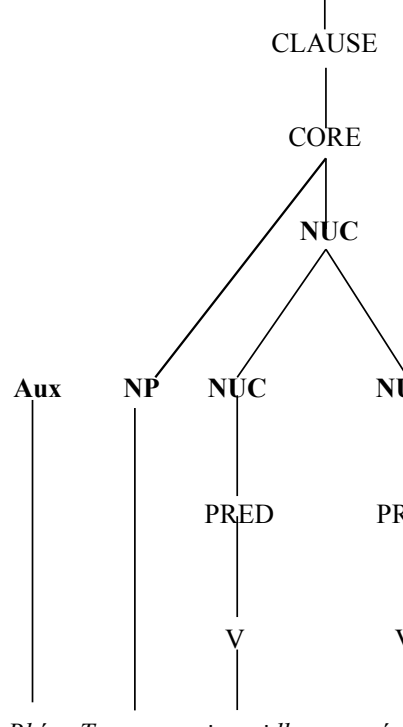

Bhí Trevors ag iarraidh éalú trasnanabpairceanna

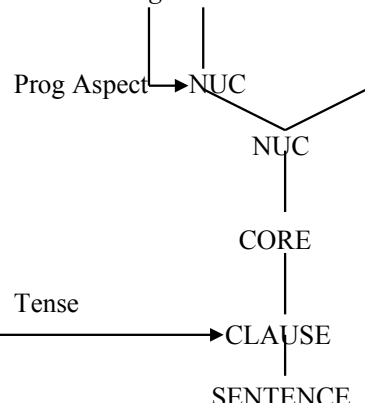

Figure 5: RRG projection of example (44) mé as

$$
\text { iarraidh }
$$


(46) Tá cúr ag tosai ag tiocht orthu
AUX-PRS froth:N at:PreP starting:VN at:PrEP coming:VN on:PREP+3PL LIT: A froth is starting coming on them.

Froth is starting to come on them.

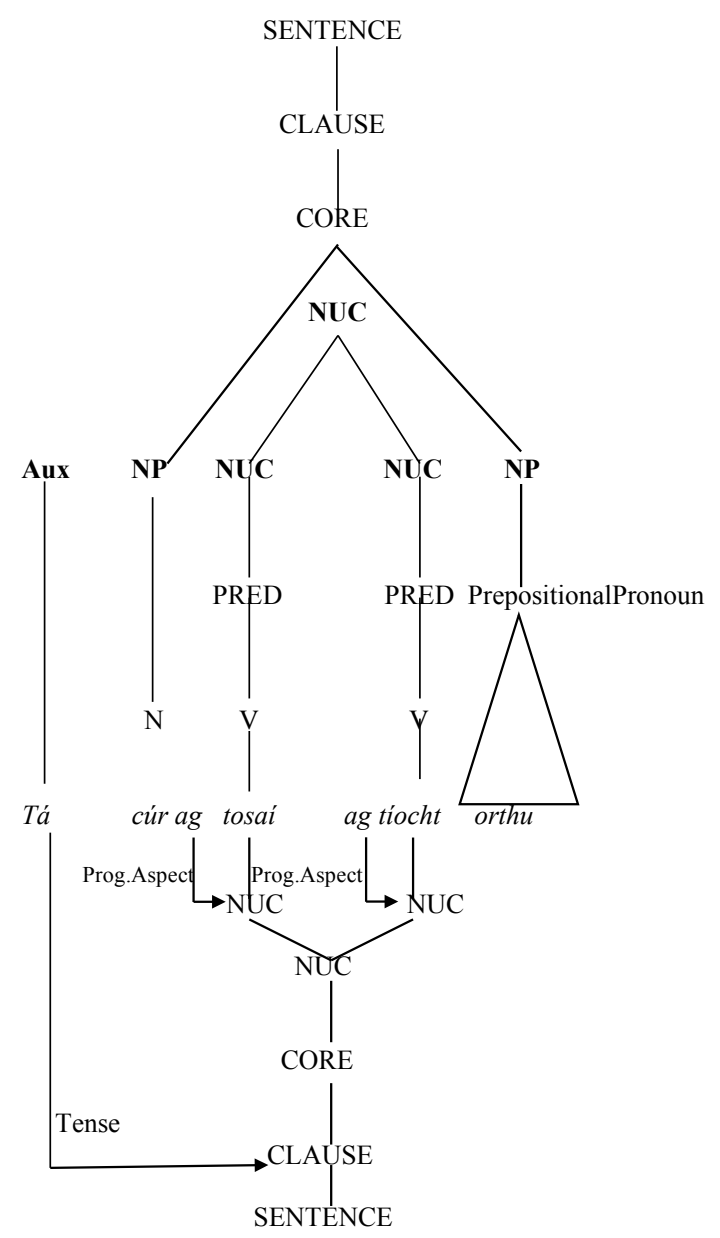

Figure 7: RRG projection of example (46)
The constructional schema for the Irish nuclear juncture LVC type with nuclear cosubordination is indicated in (47), with the constructional schema for the auxiliary verb construction that utilises light verbs shown in (48).

(47) Constructional schema for the Irish Light Verb Construction

\begin{tabular}{|c|c|}
\hline CONSTRUCTION: & Irish Light Verb Construction \\
\hline \multicolumn{2}{|l|}{ Syntax } \\
\hline Juncture: & nuclear \\
\hline Nexus: & cosubordination \\
\hline Construction type: & $\begin{array}{l}\text { light verb } \\
{[\text { Clause }[\text { CORE NP }[\text { NUC }[\text { NUC...] [NUC...] ] NP...]...] }}\end{array}$ \\
\hline PSA: & $\begin{array}{l}\text { Immediate post verbal direct core argument according to } \\
\text { actor-undergoer hierarchy and RRG linking principles }\end{array}$ \\
\hline \multirow[t]{3}{*}{ Linking: } & Link the NUCs to a single CORE \\
\hline & If the verb in NUC2 is transitive \\
\hline & Then its logical structure may assign 2 macroroles. \\
\hline Morphology: & The $V_{2}$, the matrix verb, takes $V N$ form \\
\hline Semantics: & [PRED NUC1 $]$ PHASE-CHANGE [PRED \\
\hline Pragmatics: & unspecified \\
\hline
\end{tabular}

(48) Constructional schema for the Irish Auxiliary Verb Construction

\begin{tabular}{|c|c|}
\hline CONSTRUCTION: & Irish Aux with Light Verb Construction \\
\hline Syntax & \\
\hline Juncture: & nuclear \\
\hline Nexus: & cosubordination \\
\hline Construction type: & $\begin{array}{l}\text { Auxiliary verb } \\
\text { [Clause }[\text { CORE Aux NP }[\text { NUC }[\mathrm{NUC} \ldots][\mathrm{NUC} \ldots . .] \text { ] NP...]...] }\end{array}$ \\
\hline PSA: & $\begin{array}{l}\text { Immediate post Aux direct core argument according to } \\
\text { actor-undergoer hierarchy and RRG linking principles }\end{array}$ \\
\hline Linking: & Link the NUCs to a single CORE \\
\hline Morphology: & The LV and Matrix verb both take VN form as [Aux VN VN] \\
\hline Semantics: & $\begin{array}{l}{\left[\text { PRED }_{\text {Nuc1 }}\right] \text { PHASE-CHANGE }\left[\text { PRED }_{\text {NuC2 }}\right]} \\
\text { Domain of Aux is tense, aspect, voice, negative polarity }\end{array}$ \\
\hline Pragmatics: & unspecified \\
\hline
\end{tabular}

We now briefly review the RRG approach to characterising complex predicates. 


\section{The RRG approach to characterising complex predicates}

We have mentioned earlier that the RRG model posits three nexus relations (coordination, subordination and cosubordination) between clauses in complex sentences. We also noted (49) that related to nexus relations is the nature of the units being linked, the juncture types within RRG.

\begin{tabular}{|l|l|}
\hline Nuclear juncture & {$[$ CORE $\ldots[$ NUC $\ldots] \ldots+\ldots[$ NUC $\ldots] \ldots]$} \\
\hline Core juncture & {$[$ CLAUSE $\ldots[$ CORE $\ldots] . .+\ldots[$ CORE $\ldots] \ldots]$} \\
\hline Clause juncture & {$[$ SENTENCE $\ldots[$ CLAUSE $\ldots] \ldots+. .[$ CLAUSE $\ldots] \ldots]$} \\
\hline
\end{tabular}

Of particular interest to us here in our examination of Irish light verb constructions and complex predicates is the nuclear juncture. In a nuclear juncture, a number of nuclei combine to form a single, complex nucleus with a single set of core arguments. In nuclear junctures all of the arguments of the component verbs are pooled to create a single set of core arguments for the derived complex nucleus. The syntactic juncture-nexus types are used to express certain semantic relations between the units in the juncture, for example, causation, purpose and temporal sequence. A subset of interclausal semantic relations (50) is relevant for this discussion - those to do with phase and sub-event modification.

(50) Formal characterisation of relevant subset of interclausal semantic relations

$$
\begin{aligned}
& \text { Phase: BECOME/INGR, KEEP, TERMINATE } \\
& \text { Modifying } \\
& \text { subevents: } \\
& \text { 1: manner do'( } \mathrm{x},\left[\text { MOTION'(x)] } \text {. }^{\wedge}[\text { [MANNER.OF.MOTION'(x)] }\right. \\
& \text { 2: motion } \quad \text { do' }^{\prime}\left(\mathrm{x},\left[\text { MOTION'}^{\prime}(\mathrm{x})\right] \ldots \wedge^{\wedge}\left[\text { pred }_{2} \mathbf{y}^{\prime}(\mathrm{x},(\mathrm{y}))\right]\right) \\
& \text { 3: position do' }\left(\mathrm{x},\left[\text { STANCE' }^{\prime}(\mathrm{x})\right] \ldots{ }^{\wedge}\left[\operatorname{pred}_{2} \mathbf{2}^{\prime}(\mathrm{x},(\mathrm{y}))\right]\right. \\
& \text { 4: means } \text { do' }^{\prime}\left(\mathrm{x},[\ldots] \ldots{ }^{\wedge}\left[\operatorname{pred}_{2}(\mathrm{x}, \mathrm{y})\right]\right)
\end{aligned}
$$

The semantic relations form a continuum expressing the degree of semantic cohesion between the propositional units links in the complex structure (Van Valin (2005: 208) That is, the degree to which they express components of a single action or event, or discrete actions or events. The syntactic linkage relations are posited within RRG to be ranked hierarchically as a function of the strength of the syntactic bond between the units.

\section{Discussion}

We have argued for the nexus-juncture type of nuclear cosubordination and for Irish light verbs that the interaction of the cohesion continuum of semantic relations with the hierarchy of clausal linkage across nexus-juncture types is at the strongest pole with the semantic relations covering phase and modifying subevents. We have also demonstrated that an account of Irish light verbs is within the domain of nuclear cosubordination. Within this account of Irish light verbs and nuclear junctures, the argument structures of the component logical structures are pooled to yield the composite arguments of the structure of the entire logical structure and, therefore, the logical structure maps into a single core.

Furthermore, the discussion on the Irish light verb supports the idea that these ligh verb constructions are formed pre-syntactically in the lexicon. We argue towards thi conclusion based on the following criteria as to what constitutes lexical behaviours. In RRG a criteria distinction is made between lexical and syntactic phenomena (Van Valin 1997: 389-392, 667 and Van Valin 2005: 158-160). That is, in RRG a phenomenon is considered to be lexical if it meets the criteria in (51)

(51) Diagnostics of lexical phenomenon in RRG:

a) changes the logical structure and aktionsarten properties of the event

b) affects the argument structure of the predicate,

c) alters the semantic construal of the predicate, and

d) affects the actor and undergoer assignment in the semantics to syntax linking system (Van Valin 2005: 136ff and 149ff)

(52) Diagnostic of syntactic phenomenon in RRG

a) Mapping between macroroles and the syntactic representation

Correspondingly if the phenomenon corresponds to (52), the mapping between macroroles and the syntactic representation, it is referred to as syntactic phenomenon since this affects the selection of the privileged syntactic argument and the linking between macroroles (for example, actor and undergoer, active vs. periphrastic passive) and the subsequent morphosyntactic realisation of the macroroles and the ther clausal core arguments. 
We can see from the discussion earlier on the patterns of occurrence of light verbs that the formation of these constructions meets the diagnostic criteria for lexical phenomena. That is, the fusion of the argument structure of the light verb and matrix verb within a nuclear cosubordination relationship; it affects the predicate's Aktionsarten class and its associated logical structure; it contributes semantic content, and, via the linking system, modulates the actor-undergoer assignment.

The parameters of variation we have considered in our discussion of the patterns of occurrence of LVCs in Irish, and the AVCs that utilise light verbs, are (53):

(53) The parameters of variation of Irish light verbs

1. The LVC constitutes a single event predication.

2. The phenomena of light verbs and LVCs are treated as lexical in Irish

3. The single event predication and associated logical structure are input to the (RRG) linking system.

4. Light verbs can occur in LVCs and also auxiliary verb constructions.

5. The single marking of tense is on the light verb in the LVC (and on the Aux in the AVC) that employs the LV. This is evident in the RRG operator projection in a structural diagram of the LVC

6. The Aux in the AVC when a LV is employed also records the single marking of tense. This is evident in the RRG operator projection in a structural diagram of the AVC.

7. The $\mathrm{LV}$ in the $\mathrm{AVC}$ takes the VN morphosyntactic form, as well as the matrix verb, which is also in $\mathrm{VN}$ form.

8. Progressive aspect is recorded in the AVC that employs the LV through use of a preposition ag followed by the $\mathrm{LV}$ in $\mathrm{VN}$ form. This is evident in the RRG operator projection in a structural diagram of the AVC.

9. The LV is semantically bleached with respect to event type and event attributes.

10. The matrix verb in the LVC is morphologically marked as a verbal noun (This is a common feature of Celtic languages)

11. The class of light verbs is isomorphic with the class of phase verbs
12. Verbs of motion and path are excluded from acting as light verbs in a LVC or AVC.

13. The LVC can occur within an impersonal passive construction.

We have demonstrated this across light verb constructions and those auxiliary verb constructions that use the light verb.

\section{References}

AKHENVALD, A.Y AND R.M DiXon. 2006. Serial verb Constructions. Explorations in Linguistic Typology. (Oxford Linguistics). Oxford: Oxford University Pres.

ALsina, ALEX, JoAn BRESNAN AND PETER SelLS (eds.). 2001. Complex Predicates. (Center for the Study of Language and Information - Lecture Notes). Stanford, California: CSLI.

ANDERSON, G. S. 2006. Auxiliary Verb Constructions. Oxford Studies in Typology and Linguistic Theory. (Ox.ord Linguistics). Oxf Cons: Oxford Unis. Ox rity Press.

BNIICK, Robert. 1991. Time and the verb: a guide to tense and aspect. New York: Oxford

UT, Mrisy.

The light verb jungle. [Accessed in February 2014]

harvard-work.pd

ButT, MIRIAM. 1995. The Structure of Complex Predicates in Urdu. Stanford, California: CSL

Publications.

ButT, MiRIAM, AND GiLLIAN RAMCHAND. 2003. Complex Aspectual Structure in Hindi/Urdu. In The Syntax of Aspect, ed. Nomi Ertishik-Shir and Tova Rappaport. Oxford: Oxford University Press. CHRISTIAN BROTHERS. 1997: New Irish Grammar. Dublin: C.J. Fallon-Mount Salus Press.

(O)

Aspectual Interpretation (Oxford Studies in Theoretical Linguistics). Oxforiving Thematic and Press.

REED, F. Alice. 1979. The semantics of English aspectual complementation. Dordrecht: D. Reide

Publishing Company.
HopPER, Paul J., and Elizabeth C. Traugott. 1993. Grammaticalization. Cambridge: Cambridge

University Press

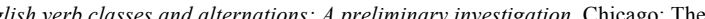

OLAN, Brian. 2012a. The structure of Irish: A functional account. Sheffield: Equinox

NOLAN, Brian and Elke Diedrichsen. 2013. 'Linking Constructions into functional linguistics - The role of constructions in RRG grammars'. [Studies in language Companion Series]. Amsterdam and New York: John Benjamins Publishing Company.

OSIADHAIL, Micheál. 1996: Learning Irish. New Haven \& London: Yale University Press.

TRATANI, Kiyoko. 2002. The morphosyntactic structure and logical structures of compound verbs in Japanese. PhD Thesis. University of New York at Buffalo.

60. Amsterdam. John Benjamins.

C ALIN, Robert D. 2005: Exploring the Syntax-Semantics Interface. Cambridge:

Cambridge University Press VAN VALIN, R. and R. LaPolla. 1997: Syntax: Structure, meaning and function. Cambridge:
Cambridge University Press. 
About the author

Dr. Brian Nolan is Head of School of Informatics and Engineering at the Institute of Technology Blanchardstown, Dublin in Ireland. The research interests of Dr. Nolan include computational approaches to speech and language processing; computational linguistics, linguistic theory at the morphosyntactic-semantic interface, argume structure and valence, constructions in grammar, event structure in languge and the chitecture of the lexicon. His linguistic work has been in the functionl linguistic chich ling o Role and Reference Grammar. Recent computing / computational linguistic /linguistic reserch has cocen supporting application suite for mobile and distributed command and control of robotic devices using speech recognition as the core enabling technology; (2) The development of a rule-based Arabic to English machine translation engine that uses Role and Reference Grammar as the linguistic model supporting an interlingua bridge; (3) The investigation of linguistic models to underpin Irish Sign Language Avatars and conversational software agents; and (4) The role and significance of constructions in a functional model of linguistics, from lexicon to clause.

Dr. Brian Nolan is the author of a book, published in 2012 by Equinox, UK, on the linguistic structure of Irish in a Role and Reference Grammar account entitled: The structure of Irish: A functional account. In December 2013 his (co-edited) volume was published by Benjamins: Linking constructions into functional linguistics - The role of constructions in grammar. His most recent (co-edited) Benjamin volume on computational linguistics and linguistic theory, Language Processing and Grammars: The role of functionally oriented computational models appeared in April 2014. At present, he is co-editing a Benjamins book of collected papers from internationa authors, on Causation, transfer and permission in linguistic theory, to appear in late 2014. Dr. Nolan has over 40 years experience nationally and internationear in late the computer industry, with almos 2 decalos in ace and is also a widely published professional linguist. 